\title{
Evidence of optically-induced degradation in gallium nitride optoelectronic devices
}

\author{
C. De Santi, ${ }^{1,2}$ A. Caria,${ }^{1}$ N. Renso, ${ }^{1}$ E. Dogmus, ${ }^{3}$ M. Zegaoui, ${ }^{3}$ F. Medjdoub,${ }^{3}$ G. \\ Meneghesso, ${ }^{1}$ E. Zanoni, ${ }^{1}$ and M. Meneghini ${ }^{1}$ \\ ${ }^{1}$ Department of Information Engineering, University of Padova, via Gradenigo 6/b, Padova, 35131, Italy \\ ${ }^{2}$ Centro Giorgio Levi Cases, University of Padova, Via Marzolo 9, Padova, 35131, Italy \\ ${ }^{3} I E M N-C N R S$, Avenue Poincaré CS 60069, Villeneuve d'Ascq, 59652, France
}

With this paper, we provide experimental evidence that gallium nitride-based optoelectronic devices can be affected by a photon-driven degradation mechanism unrelated to the more common catastrophic optical damage. The role of current in the degradation is excluded by carrying out stress tests under laser irradiation in open-circuit configuration; the role of temperature is ruled out by additional tests carried out at roughly the same temperature reached under optical excitation, showing a different degradation mode. Given the high bond strength of $\mathrm{GaN}$, a degradation caused by direct lattice damage and creation of vacancies is unlikely. A more likely cause is the de-hydrogenation of gallium vacancies, that causes an increase in opticallyactive defects and requires a removal energy lower than the photon energy.

Understanding the degradation mechanisms of GaN-based optoelectronic devices is of fundamental importance for the development of reliable LEDs and lasers. Most papers in the literature focused on the degradation processes induced by high temperatures and by current flow ${ }^{1-8}$. On the contrary, only few papers investigated the degradation processes driven by the optical field, and all of them focused on laser diodes, where the optical field is more intense and may lead to catastrophic optical damage $^{9-12}$. Tests investigating a possible gradual degradation under moderate photon fluencies were never carried out before, but they are crucial in understanding if photons, other than electrons (current) and phonons (temperature) may be a possible source of degradation in GaN-based optoelectronic devices. This is especially relevant for UV devices, where the photon energy is high.

Commonly-reported optically-induced degradation effects include the gradual degradation of the dielectric mirror coatings of laser diodes, due to an environment-related deposition and/or oxydation ${ }^{9}$, affecting even devices without mirror coatings ${ }^{10}$, direct damage to the mirror coatings ${ }^{11}$ and catastrophic optical damage (COD) in the semiconductor due to a temperature increase $^{12}$. The onset of COD is usually described as follows: light absorption at non-radiative recombination centers causes the generation of heat, leading to a positive feedback due to bandgap narrowing and/or additional increase in defect concentration $^{13}$. Tomiya et al. suggested that the root cause is the current flow, given the lack of degradation in devices with a 
current injection-free area ${ }^{13}$. Cohen et al. reported the results of some tests on laser-grade InGaN multi-quantum wells with peak emission at roughly $405 \mathrm{~nm}$, optically pumped by an external $355 \mathrm{~nm}$ pulsed laser at very high power densities, from 20 $\mathrm{kW} / \mathrm{cm}^{2}$ to $1 \mathrm{MW} / \mathrm{cm}^{2} .{ }^{14}$ They showed the creation of droplets and narrow streaks in the region where the stimulated emission was the highest, but their density in the most heavily damaged region was several orders of magnitude lower than the expected crystalline defect density, therefore they should not lead to an increase in Shockley-Read-Hall (SRH) recombination. They concluded that the generated defects may play a role when they short the pn junction, and additionally reported that in regions with low gain no degradation occurred until excitation levels of several $\mathrm{MW} / \mathrm{cm}^{2}$; however, they tested a very high power pulsed condition in a structure with gain excited with photons of energy higher than the bandgap, and therefore not representative of the gradual degradation of an optoelectronic device under nominal continuous wave operation.

Other optical damage tests were reported on bare material (not fully-processed devices) to investigate the laser-induced damage threshold (LIDT). Eliseev et al. provided evidence of laser-induced surface ablation in epitaxial gallium nitride caused by sub-picosecond pulses at $400 \mathrm{~nm}$ (i.e. below the energy gap) ${ }^{15}$, and Elhadj et al. ascribed to heating the damage caused to silicon-doped GaN by $1064 \mathrm{~nm}$ high-power laser pulses ${ }^{16}$, leading to a solid-vapor phase change ${ }^{17}$. Ščiuka et al. tested the LIDT of InGaN layers with different indium molar fraction, and report the possible occurrence of a melting and re-solidification process, as well as the formation of small metallic gallium islands ${ }^{18}$.

The aim of this work is to demonstrate the presence of a non-catastrophic photon-driven degradation mechanism in GaNbased optoelectronic devices stressed under moderate laser beam, at carrier densities compatible to those reached during normal operation. To this aim, we analyzed test structures optimized to enhance the light collection efficiency, namely high-periodicity (25 pairs) $\operatorname{In}_{0.15} \mathrm{Ga}_{0.85} \mathrm{~N} / \mathrm{GaN}$ multi-quantum wells grown on a sapphire substrate, that can be used as elements in multi-junction solar cells ${ }^{19}$, as high-power photodetectors ${ }^{20}$ or as receivers in laser-based wireless power transfer systems ${ }^{21}$ and in visible light communication (VLC) LiFi systems ${ }^{22}$. Additional details on the device structure and growth can be found in the paper by Dogmus et al. $^{23}$. The optical excitation for the stress tests was provided by a $405 \mathrm{~nm}$ high power laser diode in closed-loop optical feedback configuration, to keep the optical power on the DUT constant during the whole test (see ref. ${ }^{21}$ for a complete description), and the chosen excitation optical power density is $361 \mathrm{~W} / \mathrm{cm}^{2}$, on an elliptical spot. The devices were kept in open circuit condition, i.e. electrically disconnected, to prevent any current-related degradation. All the reported tests are carried out in air.

Fig. 1 shows the results of 486 uninterrupted hours of stress. Compared to the virgin device (black line), after stress (red line) an increase in the reverse leakage and forward leakage at low bias is clearly visible, evidence for the creation of deep 
levels that act as leakage paths ${ }^{24,25}$. This degradation affects the optical performance of the device, as confirmed by the falsecolors monochromatic photoluminescence (PL) maps in Fig. 2, recorded at $437 \mathrm{~nm}$ under resonant excitation with a $405 \mathrm{~nm}$ laser diode. In these same-scale images, after stress (Fig. 2 (b)) a reduction in the PL signal in the region where the laser was focused can be noticed compared to the device before treatment (Fig. 2 (a) ).

In principle, the photoluminescence intensity may decrease due to a local increase in non-radiative recombination centers, which act as a SRH recombination paths for part of the photo-generated hole-electron pairs, or due to an increase in the escape of carrier from the wells. However, photocurrent can not be generated in the open-circuit condition used for this test; for this reason, since the excitation photon energy is higher than the bandgap energy only inside the quantum wells, this test confirms the creation of optically-active defects inside the quantum wells.

One could argue that the variation in PL intensity could also be caused by a variation in surface reflectivity at the PL excitation wavelength, e.g. due to a laser/driven deposit of material on top of the devices ${ }^{26}$. This would lead to a lower excitation optical power density in the degraded area. To evaluate this aspect, we measured the reflectivity map after stress. As shown in Fig. 3, the measurements taken on the degraded sample do not show any pattern that could explain the measured the PL distribution measured in Fig. 2 (b).

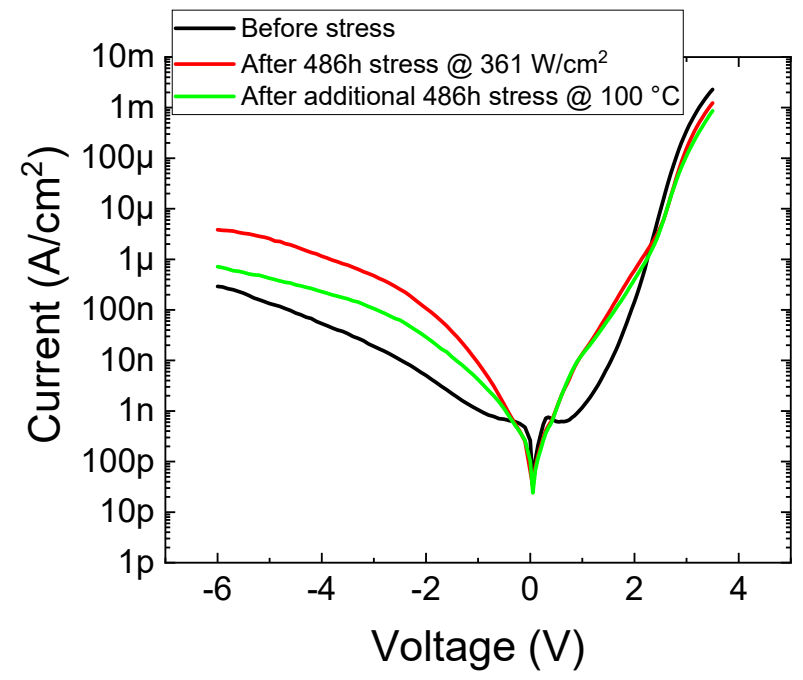

FIG. 1. Current-voltage characteristic of a solar cell before any stress (black), after $486 \mathrm{~h}$ of stress in open circuit under illumination at 361 $\mathrm{W} / \mathrm{cm}^{2}$ with a $405 \mathrm{~nm}$ laser diode in air at room temperature (red) and after additional $486 \mathrm{~h}$ of stress under no illumination in air at $100{ }^{\circ} \mathrm{C}$ (green). 

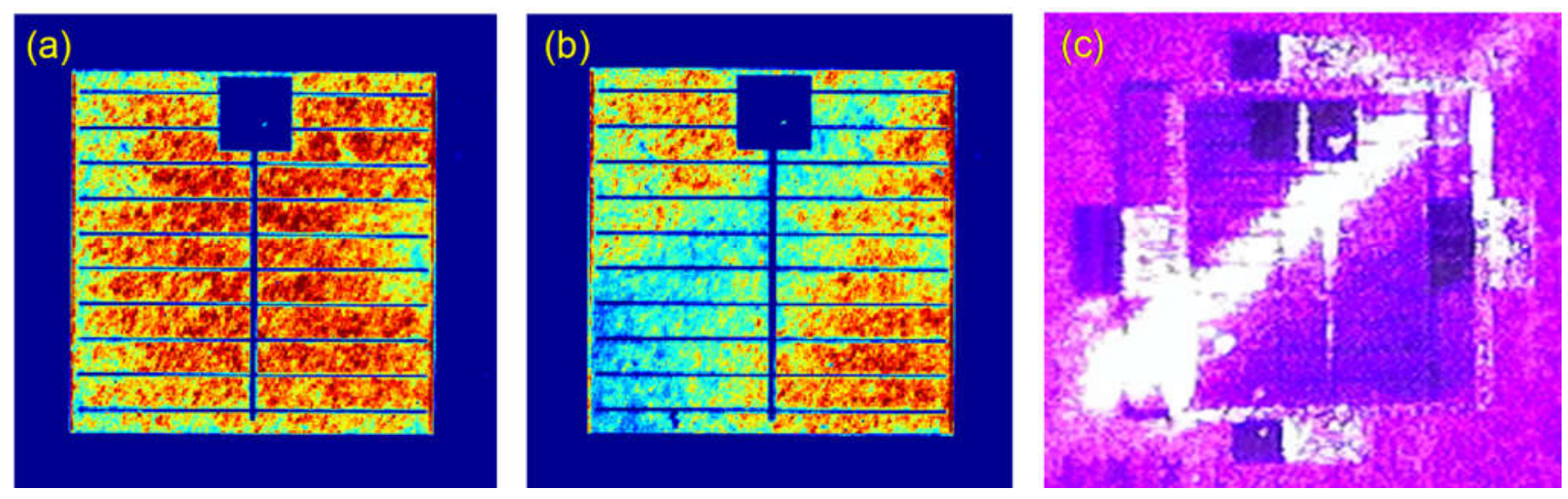

FIG. 2. False-colors photoluminescence maps recorded at $347 \mathrm{~nm}$ under resonant excitation with a $405 \mathrm{~nm}$ laser diode (a) before and (b) after optical stress at $361 \mathrm{~W} / \mathrm{cm}^{2}$ in open-circuit configuration. Both images share the same scale, where blue and red correspond to lower and higher PL intensity, respectively. (c) shows the position of the laser beam on the solar cell during stress.

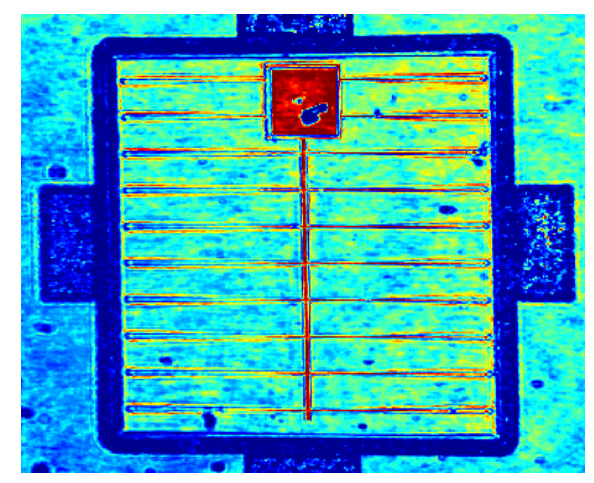

FIG. 3. Reflectivity map (red: higher, blue: lower) of the device after optical stress, showing no pattern comparable to the one in Fig. 2 (b).

The current flow can not be the cause for the degradation in this case, since no current flows through the device in opencircuit condition. An additional cause of degradation could be the temperature, that can significantly increase in the illuminated area. We measured the temperature of the device under stress by means of a FLIR A35 IR thermal camera, obtaining a peak temperature value of $30^{\circ} \mathrm{C}$. IR thermography may lead to inaccurate results, due to the limited spatial resolution and therefore to the averaging at the same detector pixel of regions with higher and lower temperature. At the optical power level and with the excitation spot size used during the stress, we can estimate a worst-case temperature error of $\approx 60{ }^{\circ} \mathrm{C}$, according to the literature $^{27}$. The real error is lower, since the heated area is significantly larger in our case and leads to a lower resolutionrelated inaccuracy. Additionally, the $60^{\circ} \mathrm{C}$ estimate is based on the assumption that all the stress optical power is absorbed and contributes to the temperature increase, whereas the collection efficiency is not $100 \%$ due to the surface reflectivity ${ }^{28,29}$ and to the partial absorption ${ }^{30,31}$. Anyway, given a worst-case estimated temperature of $90{ }^{\circ} \mathrm{C}$, to investigate the effect of the 
temperature as a possible source for the degradation we carried out a stress test on a virgin device without any optical excitation at $100^{\circ} \mathrm{C}$, i.e. a higher temperature, for the same amount of time.

Remarkably, a purely thermal stress does not cause any leakage increase in the electrical characterization of the device (see Fig. 4), suggesting that the temperature is not responsible for the degradation reported under optical excitation. The analysis of the photoluminescence maps before and after stress provides additional information on the degradation process induced by temperature. Fig. 5 (a) shows the spatially-resolved amount of degradation, which is higher at the edges and lower at the center. Since the devices are not passivated, this result is compatible with the intake of impurities from the environment, which behave as non-radiative recombination centers. To confirm whether or not this is a different degradation mechanism, we carried out the same experiment on the same device which was previously optically stressed. As shown in Fig. 1, after the additional purely thermal stress (green curve) the leakage current compared to the value after the optical stress (red curve) is not increased and even lowered, suggesting a partial annealing of the defects generated during the optical stress. Additional insight can be obtained from the degradation PL map in Fig. 5 (b): in this case, the map shows the spatial distribution of the degradation caused only by the thermal stress on the device that underwent the previous optical stress. The spatial distribution of the degradation is the same as the one reported for the device stressed only thermally in Fig. 5 (a), confirming that the thermal treatment has a negative impact on the optical performance of the device, and a stronger impact at the edges. The most important information comes from the complete uniformity over the whole surface of the degradation pattern. This result confirms that the thermal stress causes a different degradation mode with respect to the optical stress, because if the degradation mode is the same we would expect a lower amount of thermal degradation in the lower left - upper right diagonal, which was severely damaged during the optical stress.

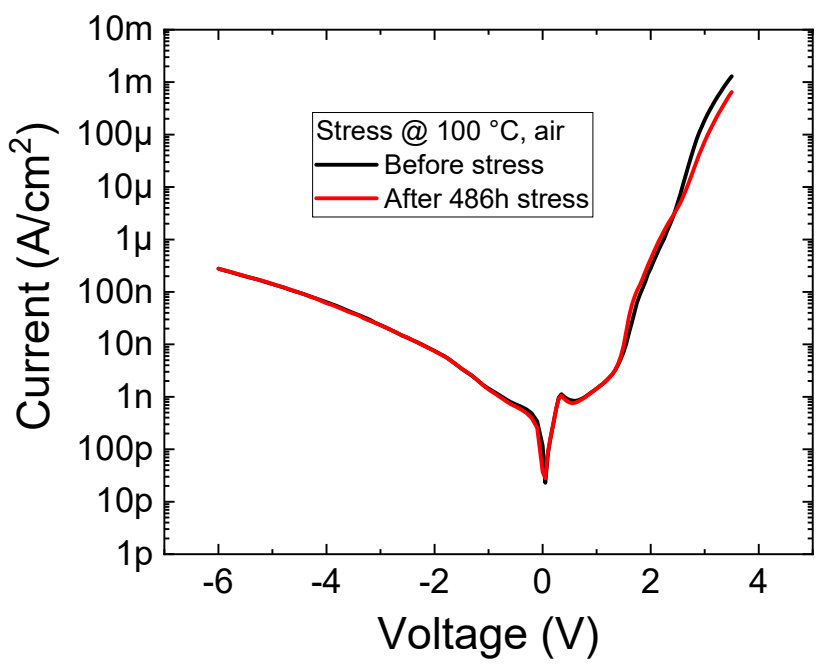


FIG. 4. Current-voltage characteristic of an additional solar cell before stress (black) and after $486 \mathrm{~h}$ of stress under no illumination in air at $100{ }^{\circ} \mathrm{C}$ (red).

(a) Thermally stressed

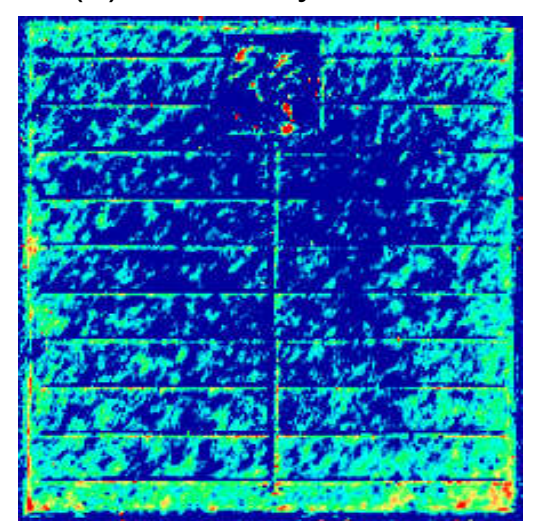

\section{(b) Optically and thermally stressed}

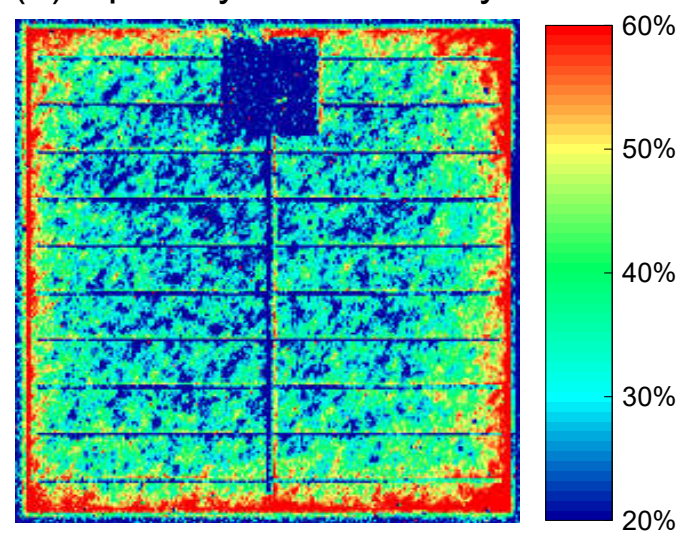

FIG. 5. Spatially-resolved PL degradation maps, recorded at $437 \mathrm{~nm}$ under resonant excitation at $405 \mathrm{~nm}$, reporting the degradation caused by $486 \mathrm{~h}$ of thermal stress at $100{ }^{\circ} \mathrm{C}$ under no illumination in air on (a) an untreated device and (b) a device previously stressed for $486 \mathrm{~h}$ of stress in open circuit under illumination at $361 \mathrm{~W} / \mathrm{cm}^{2}$ with a $405 \mathrm{~nm}$ laser diode in air at room temperature.

Therefore, in the optical stress a possible role of current flow can be excluded due to the open-circuit configuration, and the temperature is not causing the same degradation mode. Since electrons and phonons are ruled out as possible origin for the degradation, the only remaining energy source in the test are the photons. One possible mechanism that can lead to the degradation is the absorption of photons by the gallium or nitrogen atoms of the lattice, breaking the atomic bond and generating vacancies. The GaN bond strength is rather high, evaluated at $8.9 \mathrm{eV}^{32,33}$, whereas the energy of the photon used in the stress test is only $3.06 \mathrm{eV}$. For this reason, direct lattice damage is an unlikely event. A second possibility is the de-hydrogenation of gallium vacancies. This process is known to negatively affect the optical performances of a device, as confirmed by positron annihilation spectroscopy experiments ${ }^{34}$. Unfortunately, no data are available in the literature on the energy required to remove one hydrogen atom from a gallium vacancy in InGaN, but the value was calculated for GaN by using the density-functional theory in the local-density approximation and found to be lower than the energy gap ${ }^{35}$. Therefore, one photon may be absorbed by a $\mathrm{V}_{\mathrm{Ga}}-\mathrm{H}_{\mathrm{n}}$ complex, thus transferring the energy required to remove one hydrogen atom. This can result in the creation of deep acceptor levels in the gap, which are responsible for an higher SRH recombination ${ }^{34}$. This hypothesis is supported by previous stress tests carried out on the same devices under short circuit condition, which highlighted an increase in the concentration of optically-active gallium vacancies ${ }^{36}$. Other works suggest the possible de-hydrogenation of other complexes, such as $\mathrm{O}_{\mathrm{N}}-\mathrm{H}$, but no correlation of this process with a decrease in the optical performance is provided ${ }^{37}$. 
In summary, the presence of an optically-induced degradation mechanism caused by photon flow in the quantum wells was experimentally demonstrated. A current flow is not present during the stress due to the open-circuit condition. Stresses at the same temperature reached during the optical stress but without any optical degradation show a different degradation mechanism, probably related to the intake of impurities from air, and exclude its possible role. The damage is not likely to be caused by destruction of the atomic bonds, that requires an energy significantly higher than that of photons. Degradation is ascribed to the de-hydrogenation of gallium vacancies, a process that lowers the optical efficiency of the device due to the creation of Shockley-Read-Hall recombination centers. According to previous reports ${ }^{34}$, this process requires an energy lower than the photon energy.

\section{ACKNOWLEDGMENTS}

This research activity was partially supported by University of Padova under research grant BIRD167052/16, "Solar cells based on InGaN for high efficiency photovoltaics and wireless power transmission”, and by the Interdepartmental Centre Giorgio Levi Cases under research grant 2017LC2, “Celle solari basate su InGaN per fotovoltaico ad alta efficienza e trasmissione wireless dell'energia".

\section{REFERENCES}

${ }^{1}$ M.-H. Chang, D. Das, P.V. Varde, and M. Pecht, Microelectron. Reliab. 52, 762 (2012). DOI:

10.1016/j.microrel.2011.07.063.

${ }^{2}$ C. De Santi, M. Meneghini, G. Meneghesso, and E. Zanoni, Microelectron. Reliab. 64, (2016). DOI:

10.1016/j.microrel.2016.07.118.

${ }^{3}$ C. De Santi, M. Meneghini, D. Gachet, G. Mura, M. Vanzi, G. Meneghesso, and E. Zanoni, IEEE Trans. Nanotechnol. 15, (2016). DOI: 10.1109/TNANO.2016.2520833.

${ }^{4}$ L.X. Zhao, E.J. Thrush, C.J. Humphreys, and W. a. Phillips, J. Appl. Phys. 103, 024501 (2008). DOI: 10.1063/1.2829781.

${ }^{5}$ K.K. Leung, W.K. Fong, P.K.L. Chan, and C. Surya, J. Appl. Phys. 107, 073103 (2010). DOI: 10.1063/1.3357312.

${ }^{6}$ L. Liu, M. Ling, J. Yang, W. Xiong, W. Jia, and G. Wang, J. Appl. Phys. 111, 093110 (2012). DOI: 10.1063/1.4712030.

${ }^{7}$ C. De Santi, M. Meneghini, M. Marioli, M. Buffolo, N. Trivellin, T. Weig, K. Holc, K. Köhler, J. Wagner, U.T.T. Schwarz, G. Meneghesso, and E. Zanoni, Microelectron. Reliab. 54, 2147 (2014). DOI: 10.1016/j.microrel.2014.07.073.

${ }^{8}$ M. La Grassa, M. Meneghini, C. De Santi, M. Mandurrino, M. Goano, F. Bertazzi, R. Zeisel, B. Galler, G. Meneghesso, and E. Zanoni, Microelectron. Reliab. 55, 1775 (2015). DOI: 10.1016/j.microrel.2015.06.103.

${ }^{9}$ V. Kümmler, A. Lell, V. Härle, U.T. Schwarz, T. Schoedl, and W. Wegscheider, Appl. Phys. Lett. 84, 2989 (2004). DOI: 
$10.1063 / 1.1704861$.

${ }^{10}$ T. Schoedl, U.T. Schwarz, V. Kümmler, M. Furitsch, A. Leber, A. Miler, A. Lell, and V. Härle, J. Appl. Phys. 97, 123102 (2005). DOI: 10.1063/1.1929851.

${ }^{11}$ L. Marona, M. Sarzynski, P. Wiśniewski, M. Leszczyński, P. Prystawko, I. Grzegory, T. Suski, S. Porowski, R. Czernecki, G. Kamler, A. Czerwinski, M. Pluska, J. Ratajczak, and P. Perlin, in Proc. SPIE, edited by C. Mermelstein and D.P. Bour (International Society for Optics and Photonics, 2007), p. 648504. DOI: 10.1117/12.699001.

${ }^{12}$ M. Hempel, J.W. Tomm, B. Stojetz, H. König, U. Strauss, and T. Elsaesser, Semicond. Sci. Technol. 30, 072001 (2015). DOI: $10.1088 / 0268-1242 / 30 / 7 / 072001$.

${ }^{13}$ S. Tomiya, O. Goto, and M. Ikeda, in Proc. SPIE, edited by H. Morko?, C.W. Litton, J.-I. Chyi, Y. Nanishi, and E. Yoon (2008), p. 68940N. DOI: $10.1117 / 12.767769$.

${ }^{14}$ D.A. Cohen, T. Margalith, A.C. Abare, M.P. Mack, L.A. Coldren, S.P. DenBaars, and D.R. Clarke, Appl. Phys. Lett. 72, 3267 (1998). DOI: 10.1063/1.121619.

${ }^{15}$ P.G. Eliseev, H.-B. Sun, S. Juodkazis, T. Sugahara, S. Sakai, and H. Misawa, Jpn. J. Appl. Phys. 38, L839 (1999). DOI: 10.1143/JJAP.38.L839.

${ }^{16}$ S. Elhadj, J. Yoo, R.A. Negres, M.G. Menor, J.J. Adams, N. Shen, D.A. Cross, I.L. Bass, and J.D. Bude, Opt. Mater. Express 7, 202 (2017). DOI: 10.1364/OME.7.000202.

${ }^{17}$ J.-H. Yoo, M.G. Menor, J.J. Adams, R.N. Raman, J.R.I. Lee, T.Y. Olson, N. Shen, J. Suh, S.G. Demos, J. Bude, and S. Elhadj, Opt. Express 24, 17616 (2016). DOI: 10.1364/OE.24.017616.

${ }^{18}$ M. Ščiuka, M. Dmukauskas, T. Grinys, and A. Melninkaitis, in Proc. SPIE, edited by G.J. Exarhos, V.E. Gruzdev, J.A. Menapace, D. Ristau, and M.J. Soileau (International Society for Optics and Photonics, 2012), p. 85300Y. DOI: $10.1117 / 12.977451$.

${ }^{19}$ J.-K. Sheu, F.-B. Chen, S.-H. Wu, M.-L. Lee, P.-C. Chen, and Y.-H. Yeh, Opt. Express 22 Suppl 5, A1222 (2014). DOI: 10.1364/OE.22.0A1222.

${ }^{20}$ J. Pereiro, C. Rivera, A. Navarro, E. Munoz, R. Czernecki, S. Grzanka, and M. Leszczynski, IEEE J. Quantum Electron. 45, 617 (2009). DOI: 10.1109/JQE.2009.2013140.

${ }^{21}$ C. De Santi, M. Meneghini, A. Caria, E. Dogmus, M. Zegaoui, F. Medjdoub, B. Kalinic, T. Cesca, G. Meneghesso, and E. Zanoni, Materials (Basel). 11, (2018). DOI: 10.3390/ma11010153.

${ }^{22}$ K.-T. Ho, R. Chen, G. Liu, C. Shen, J. Holguin-Lerma, A.A. Al-Saggaf, T.K. Ng, M.-S. Alouini, J.-H. He, and B.S. Ooi, Opt. Express 26, 3037 (2018). DOI: 10.1364/OE.26.003037. 
${ }^{23}$ E. Dogmus, M. Zegaoui, L. Largeau, M. Tchernycheva, V. Neplokh, S. Weiszer, F. Schuster, M. Stutzmann, M. Foldyna, and F. Medjdoub, Phys. Status Solidi 12, 1412 (2015). DOI: 10.1002/pssc.201510137.

${ }^{24}$ M. Mandurrino, G. Verzellesi, M. Goano, M. Vallone, F. Bertazzi, G. Ghione, M. Meneghini, G. Meneghesso, and E. Zanoni, Phys. Status Solidi 212, 947 (2015). DOI: 10.1002/pssa.201431743.

${ }^{25}$ M. Auf der Maur, B. Galler, I. Pietzonka, M. Strassburg, H. Lugauer, and A. Di Carlo, Appl. Phys. Lett. 105, 133504 (2014). DOI: $10.1063 / 1.4896970$.

${ }^{26}$ P. Perlin, L. Marona, P. Wisniewski, M. Leszczynski, P. Prystawko, M. Bockowski, R. Czernecki, I. Makarowa, B.

Kowalski, and T. Suski, Mater. Res. Soc. Symp. Proc. 1195, 1 (2010). DOI: 10.1557/PROC-1195-B01-04.

${ }^{27}$ I. Rossetto, M. Meneghini, T. Tomasi, D. Yufeng, G. Meneghesso, and E. Zanoni, Microelectron. Reliab. 52, 2093 (2012).

DOI: 10.1016/J.MICROREL.2012.06.132.

${ }^{28}$ N.G. Young, E.E. Perl, R.M. Farrell, M. Iza, S. Keller, J.E. Bowers, S. Nakamura, S.P. Denbaars, and J.S. Speck, Appl. Phys. Lett. 104, (2014). DOI: 10.1063/1.4873117.

${ }^{29}$ J. Bai, C.C. Yang, M. Athanasiou, and T. Wang, Appl. Phys. Lett. 104, (2014). DOI: 10.1063/1.4864640.

${ }^{30}$ M.-J. Jeng and Y.-L. Lee, J. Electrochem. Soc. 159, H525 (2012). DOI: 10.1149/2.009206jes.

${ }^{31}$ N.G. Young, R.M. Farrell, Y.L. Hu, Y. Terao, M. Iza, S. Keller, S.P. Denbaars, S. Nakamura, and J.S. Speck, Appl. Phys. Lett. 103, (2013). DOI: 10.1063/1.4826483.

${ }^{32}$ S. Porowski, Mater. Sci. Eng. B 44, 407 (1997). DOI: 10.1016/S0921-5107(96)01730-8.

${ }^{33}$ H.M. Ng, N.G. Weimann, and A. Chowdhury, J. Appl. Phys. 94, 650 (2003). DOI: 10.1063/1.1582233.

${ }^{34}$ H. Nykänen, S. Suihkonen, L. Kilanski, M. Sopanen, and F. Tuomisto, Appl. Phys. Lett. 100, 122105 (2012). DOI: 10.1063/1.3696047.

${ }^{35}$ C.G. Van de Walle, Phys. Rev. B 56, R10020 (1997). DOI: 10.1103/PhysRevB.56.R10020.

${ }^{36}$ C. De Santi, M. Meneghini, A. Caria, E. Dogmus, M. Zegaoui, F. Medjdoub, E. Zanoni, and G. Meneghesso, Microelectron. Reliab. 76-77, 575 (2017). DOI: 10.1016/j.microrel.2017.06.072.

${ }^{37}$ J. Chen, Y.S. Puzyrev, C.X. Zhang, E.X. Zhang, M.W. McCurdy, D.M. Fleetwood, R.D. Schrimpf, S.T. Pantelides, S.W. Kaun, E.C.H. Kyle, and J.S. Speck, IEEE Trans. Nucl. Sci. 60, 4080 (2013). DOI: 10.1109/TNS.2013.2281771. 
Lunghezza: $3224 / 3500$

testo: 2224

figure: 1000 